\title{
Signs of Urban Identity in the Cities of Terra d'Otranto: A Contribution to Historical Research and Issues about Conservation Practices
}

\author{
Julia Puretti \\ University of Salento, Piazza Tancredi 7, 73100 Lecce, Italy
}

\begin{abstract}
The cities of Terra d'Otranto own a stratified architectural heritage, strongly connected with the local rural resources. From 15th to 19th century important phases of urban development contributed to creating an incisive characterization of many small cities holding precious cultural traces, appreciable in the specific use of construction materials and in the peculiar image of the historic city landscapes. Steeples and church pediments can be identified as signs of urban identity, alongside monumental walls, city gates, fortified buildings and other explicit representations of religious and secular authority. Moreover squares, courtyards and surroundings of undeniable cultural interest, form a typical environmental heritage that the communities have enriched with many tangible and intangible values. In regard to the vulnerability of the building heritage, considerations on the broad scope of conservation are more important than ever, especially in relation to the required implementation of knowledge through scientific research and more attentive restoration practices on the architectural heritage of the historic cities. Ultimately, an in-depth study of the urban palimpsest is necessary for the proper identification of the features to safeguard, considering the risk of losing important testimonies for the collective memory.
\end{abstract}

Key words: Historical cities, urban identity, architectural conservation, collective memory, Terra d'Otranto, Italy.

\section{Introduction}

Situated in the Mediterranean Sea, the Salento peninsula is a territory that has been dominated by several cultures. The landscape of Terra d'Otranto owns a specific urban identity, formed by the strong relationship between rural resources and historical issues. Every city is the organic result of several parts, even not monumental, which reflect themselves as a "whole" rich in relational meanings, in a context the landscape participates within.

Against the background of a plurality of human events, urban history unfolds with its architecture and its spaces, its structures and its relationships, in a complexity of traces and memories through which it is possible to capture permanence and values, in a

Corresponding author: Julia Puretti, Ph.D. in Knowledge and Enhancement of Cultural Heritage at the Scuola Superiore ISUFI, University of Salento, research fields: urban history, and architectural restoration. continuous conditioning between cities and territory [1], where the latter also presents itself as "a complex product of technical skills, cultural choices, social and economic forces, [...] of material life and self-representation of a society" [2]. It seems to emerge a basic need to insert what is "a product of civilization" within the continuous cycle of history, of which the present is also part [3]; a need more widely expressed in the conviction that "the struggle for the defense of the heritage of the past is identified with the one for the continuity of culture, which implicitly is also continuity of memory" [4].

\section{The Urban Palimpsest}

In the cities of Terra d'Otranto the urban transformations of the modern age have laid the foundations for the characterization of a lot of small walled and open villages, creating an interesting picture of the historic city landscape, full of specific 
values and features.

Under a very elaborated architectural stratification the signs of urban identity are closely linked to the same presence of a so varied palimpsest, where buildings from previous centuries communicate with more recent ones in a harmonious context at least until the end of the nineteenth century (Figs. 1 and 2).

In the cities of southern Salento, already rich in precious archeological evidence, most of the fortified buildings are related to 15 th and 16th centuries (to the Principato di Taranto, aragonese and imperial periods) and consist of city walls, gates, towers and castles. Iconographic sources generally provide many details about emerging architectures in the urban landscape, especially between 19th and 20th centuries (Figs. 3 and 4). During 17th and 18th centuries, steeples and pediment of churches became the main visual points of the skyline, strongly linked to the decisive role that the catholic religion posed in the years of the Counter-Reformation. In the same period, in relation to a widespread process of decommissioning of the military function, many castles and fortified structures were slowly transformed into noble palaces.

Moreover, there are other elements not visible in the skyline but with an extreme intrinsic historicity as granaries pits, worship crypts and hypogea (for the processing of oil and wine) and, in general, buildings related to everyday life, which record the continuity in the practices of exploitation of a territory that for centuries has based its economy on a close link with the rural world. These elements are not always appreciable from a panoramic look but they have to be considered anyway emerging architecture to be safeguarded.

\section{Vulnerabilities}

The local calcarenitic stone is a very workable construction material, which allowed an extraordinary use in decorative inventions during the Baroque period. In every time of its history, the local calcarenitic stone posed continuous conservation issues. In a document of the century, preserved in

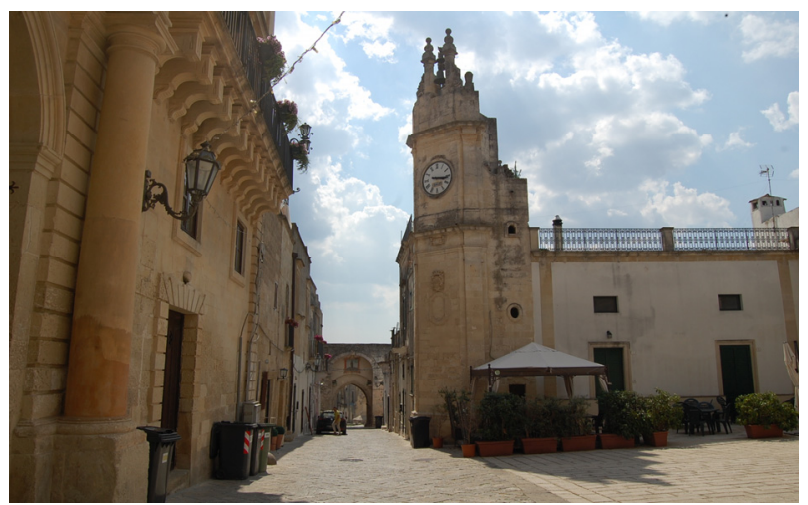

Fig. 1 Scorrano (Lecce): the 15th century Porta Terra (in the background) close to the Clock Tower of the 19th century.

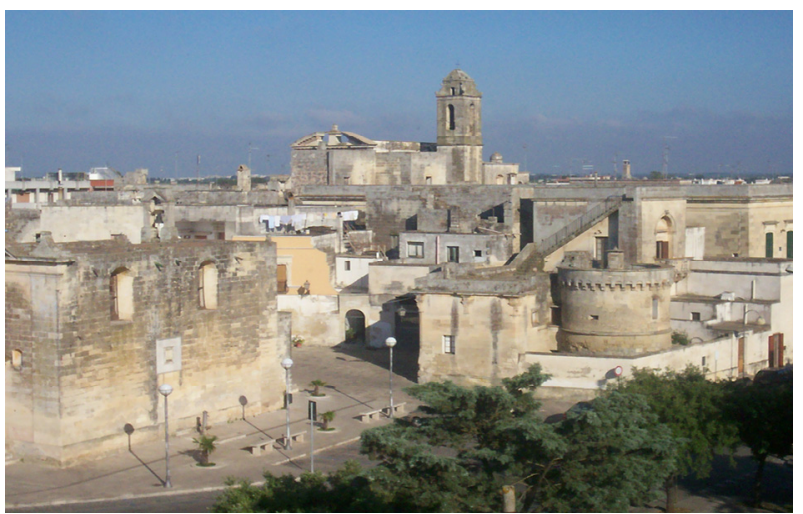

Fig. 2 Martano (Lecce): an overall view of the architectural palimpsest (15th-19th centuries) of the city. 


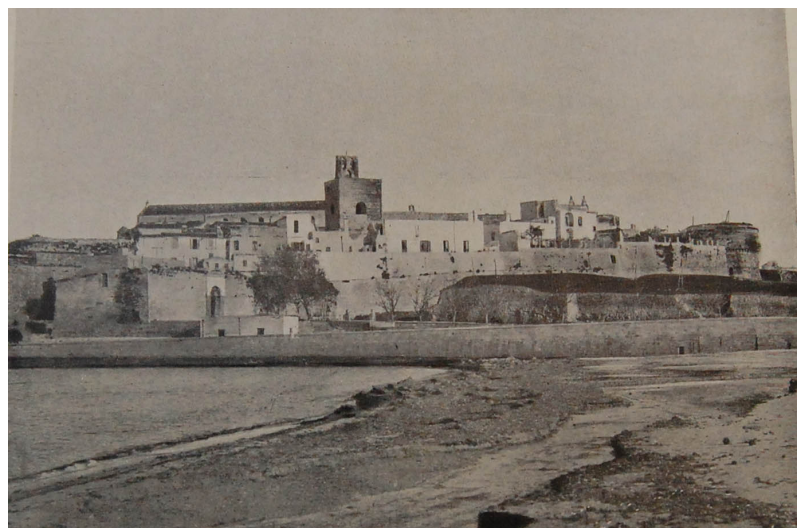

Fig. 3 Otranto (Lecce): the fortified city at the beginning of 20th century [5].

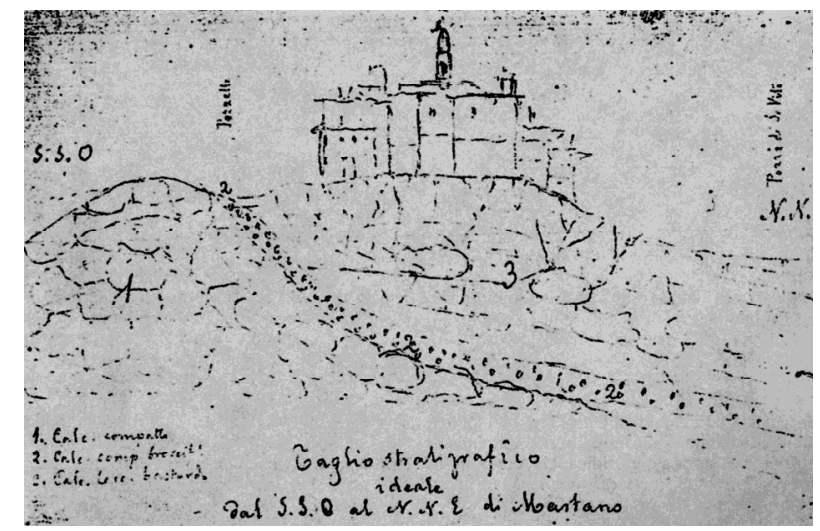

Fig. 4 Martano (Lecce): a view of the historical city in a drawing of the early 20th century (to notice the steeple detail) [6].

the State Archive of Naples and regarding the works done in the mother church of Alessano (Lecce), the calcarenitic stone is considered as a material to discard for the benefit of marble because of the said fragility [7].

Nowadays, the vulnerability of a built heritage damaged from a high level of degradation of the building stone (Fig. 5), appears clear next to the vulnerability actually exposed by the lack of knowledge about the values of a landscape palimpsest that deserves more conscious and balanced restoration interventions.

\section{Architectural Restoration Issues}

The application of different attitudes and operations in the matter of architectural restoration has damaged many times an urban heritage of very high quality, in regard of its value as historical evidence.
In the territory under consideration, in the last decades, works on the "pre-existence" haven't always been careful to the adoption of scientifically valid solutions regarding the principles that are still shared by the Italian scientific community in the field of critical-conservative restoration. There is often a reiterated different approach between monumental and environmental buildings. There are misunderstandings about the interventions in the historical cities, clearly also terminological issues inherited from the Italian national planning laws of the previous years ( $\mathrm{L}$. 1150/42, D.M. 1444/66, L. 457/78), that have dictated ways and classifications to be followed more than International Conventions and Restoration Charts. When the architectural conservation is confused with the practice of "retrieval", or with "recovery" or "urban redevelopment", the results on the historical environmental heritage are devastating. 

Research and Issues about Conservation Practices

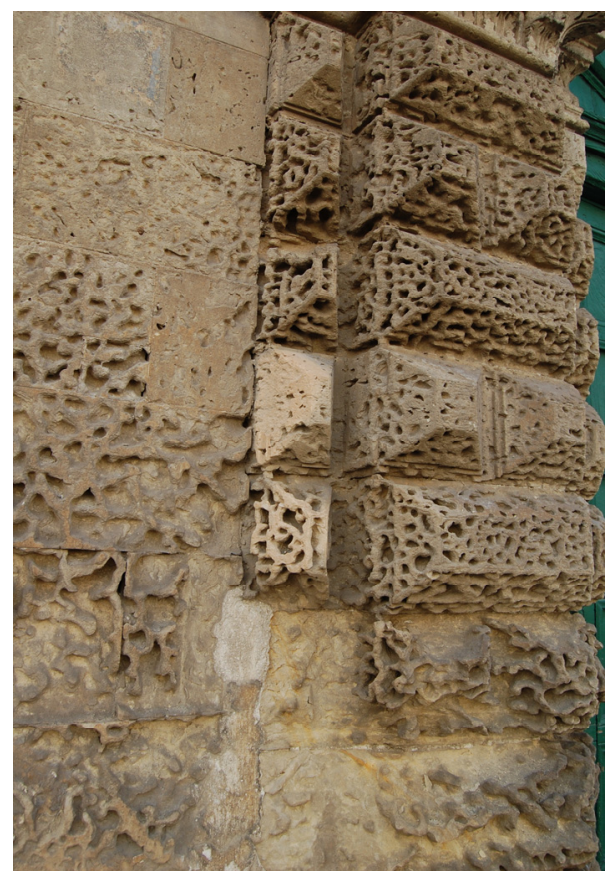

Fig. 5 A type of local limestone degradation (alveolization).

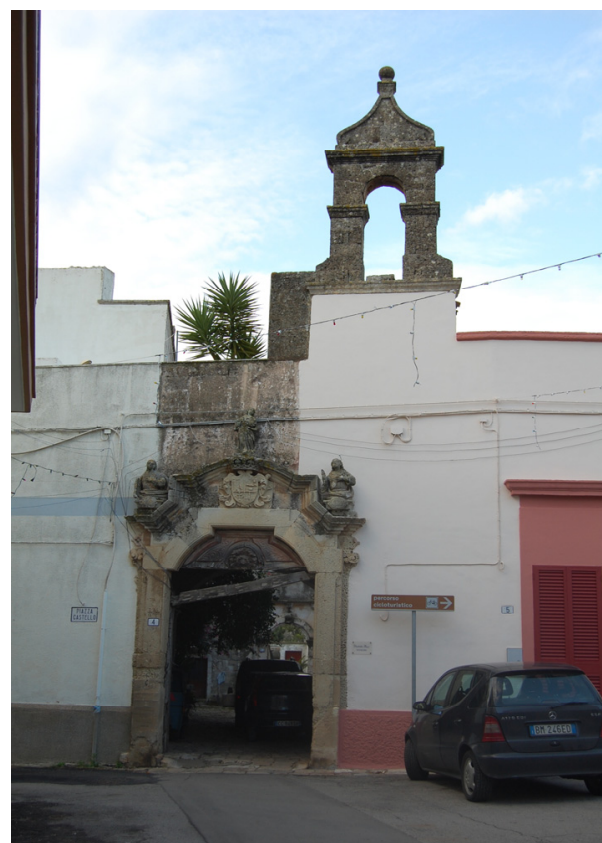

Fig. 6 Montesardo (Lecce): incongruous surface treatments on the architectural heritage of the old city. 


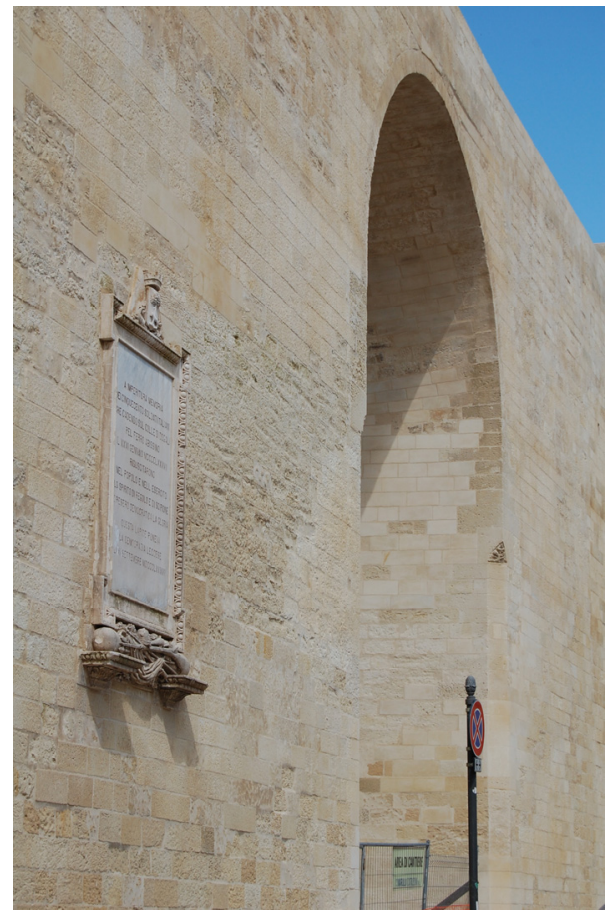

Fig. 7 Lecce: replacement of damaged segments in Porta Napoli, the monumental 16th century entrance to the city.

The lack of knowledge in many local projects is at the root of the most widespread interventions problems that undoubtedly make the complexity of the issue emerge; problems like more or less philological (and sometimes falsified) restorations, aggressive and incongruous interventions on surfaces and plasters (Fig. 6), re-inventions of historical pavements, that document the failure to respect the image, the meanings, of materials, of the construction techniques, of the historical city itself. The most common problems, related to a long-standing practical experience of interventions on environmental buildings, are associated with projects not attentive to the material values, with results that generally affect the authenticity of the architectural artifact, tending to an integration of the gaps in a completion perspective, ignoring critical approaches and in-depth analysis on the reality of architecture.

"As everybody knows, there is no actual remedy to the mutilations and damage suffered by a monument as a result of negligence or misuse; it may be repaired or even copied from life, but the uniqueness of what has gone lost will never be recovered"[8].
If the replacement of the ashlars has apparently become a normally shared practice, one cannot help but wonder about the legitimacy of the indiscriminate replacement of an authentic material to achieve a renewal that often could affect the formal values of the environmental heritage, in addition to the material instance (Fig. 7). In a certain sense, and by means of a dialectical process, each time it is a matter of evaluating which critical conservation criteria have to be renounced, in view of a "sustainable" restoration.

\section{Discussion on Historical Research}

The recognition of the historical-cultural motivations at the base of the relationships between construction and anthropic territory is a problem not easily solvable, unless to become aware that it is essentially a research task, an exercise in continuous and dialectical refinement, far from any deterministic approach [9].

Where the historical process of architecture is still philologically traceable and evident, conditions are laid for an expansion of knowledge, in the context of historical relativity, which brings together meanings 
and value judgments, but above all, promotes a shared methodology of investigation, aimed at improving conservation and enhancement of heritage [10].

If the reading of the tangible meanings of this patrimony binds to a substantial way to the sensitivity of the community, which certainly more easily recognizes the values linked to the perpetuation of an historical memory, when not deriving from the most immediate bed of aesthetic appeal, alongside it, the reading of the city, carried out with the tools of research, is very necessary for its characteristic of being an analysis that is played at different scales integrating essential interdisciplinary contributions. The instruments of historical research also include the broader work of acknowledgement and interpretation of values, so closely linked to the identification of the features necessary to define the deepest soul of an anthropic reality, in other words, of its genius loci [11].

\section{Conclusions}

All the cities of southern Salento present an architectural heritage which deserves to be protected by a strategy based on the shared understanding of its historical values and specific features [12].

In regard to the vulnerability of the building heritage, general considerations on the broad scope of conservation are more important than ever, not only in relation to natural disasters (e.g., the earthquakes occurred in Italy during the last years), but also in relation to the required implementation of knowledge through scientific research and more attentive restoration practices on the widespread heritage of historic cities.

Methodological observations concerning the need to face an in-depth study of the constructive palimpsest of the historical cities are necessary for the proper identification of the features we want to protect, considering the risk of losing important testimonies for the collective memory.

What we can expect is a challenge to the issues of conservation, at the level of planning and projects; a challenge which involves the communities and the authorities - administrators, research institutions-in the deployment of knowledge strategies and in the management of operational proposals, just catching the instances of a still operating past, even if with the eyes of the contemporary times.

\section{References}

[1] Manieri Elia, M. 1989. Architettura e mentalità dal Classico al Neoclassico. Roma-Bari: Laterza. (in Italian)

[2] Poleggi, E., and Stefani, L. 1987. "Cartografia e storia urbanistica: il contributo del catasto napoleonico." Cartografia e Istituzioni in età moderna, 1, Genova: Stamperia Brigati-Carucci: 87-104. (in Italian)

[3] Grassi, L. 1980. "Restauro." Dizionario Enciclopedico UNEDI, 27-29. (in Italian)

[4] Pane, R. 1971. "Introduzione Generale." Il Centro Antico di Napoli. Restauro Urbanistico e Piano di Intervento, I, Napoli: Esi, 3-35. (in Italian)

[5] Gigli, G. 1912. Il tallone d'Italia, II, Bergamo: Istituto Italiano d'Arti Grafiche. (in Italian)

[6] De Giorgi, G. 1981 (1st ed. 1901). Note e ricerche sui materiali edilizi adoperati nella provincia di Lecce, Galatina: Congedo. (in Italian)

[7] Grande, G. 1844. Progetto de'lavori per dar compimento alla chiesa di Alessano. State Archive of Naples, Ponti e Strade 1630. (in Italian)

[8] Carbonara, G. 2012. "An Italian Contribution to Architectural Restoration." Frontiers of Architectural Research 1: 2-9.

[9] Gadamer, H. G. 1960. Wahrheit und Methode. Tübingen: J. C. B. Mohr (Paul Siebeck). (in German)

[10] Miarelli Mariani, G. 1992. Centri Storici. Note sul Tema. Roma: Bonsignori Editori. (in Italian)

[11] Bortolotti, L. 2009. "Storia e identità dei luoghi: qualche riflessione." Storia Urbana 122: 5-25. (in Italian)

[12] Puretti, J. 2008. "Muro Leccese: città storica e conservazione." Kronos 4: 53-73; Ippoliti, A. 2009. "Storia e restauro: giudizio critico sulla realtà dell'architettura." Quaderni del Laboratorio di Restauro Architettonico ISUFI, 1, Roma: De Luca Editori, 13-6; Ippoliti, A., and Puretti, J. 2018. "Il paesaggio di Terra d'Otranto: questioni di conoscenza e conservazione." Ananke 83: 129-32. (in Italian) 